\title{
An Applicator Delivery System for Fixed-Combination Calcipotriene Plus Betamethasone Dipropionate Topical Suspension (Gel): Innovating Psoriasis Vulgaris Treatment Through Patient Collaboration
}

Gritt Rasmussen • Lene Lillevang Bech • Torben Wager Nielsen

To view enhanced content go to www.dermtherapy-open.com

Received: September 14, 2015 / Published online: November 5, 2015

(C) The Author(s) 2015. This article is published with open access at Springerlink.com

\section{ABSTRACT}

Treatment non-adherence is a complex problem encountered in all therapy areas, particularly in chronic diseases such as psoriasis vulgaris. To address adherence issues, focus is turning towards developing interventions tailored to individual patient needs. Topical therapies remain the mainstay of psoriasis treatment; however, these are associated with additional challenges where preparations may be perceived as messy, inconvenient and time-consuming. Once-daily fixed-combination calcipotriene $0.005 \%(\mathrm{Cal})$ and betamethasone dipropionate $0.064 \%$ (BD) topical suspension is a convenient and effective first-line topical psoriasis therapy. To improve the patient experience with this treatment, we undertook a program-in collaboration with patients and healthcare professionals-to develop a topical treatment delivery system that further caters to the unmet

Electronic supplementary material The online version of this article (doi:10.1007/s13555-015-0087-0) contains supplementary material, which is available to authorized users.

G. Rasmussen $(\bowtie) \cdot$ L. L. Bech · T. W. Nielsen LEO Pharma A/S, Ballerup, Denmark e-mail: gritt.rasmussen@leo-pharma.com needs of psoriasis patients. The finalized Applicator comprises: an easy to operate pump-action lever providing consistently accurate dose delivery (0.05 g of Cal/BD topical suspension/pump); a single-tip nozzle allowing for targeted, precise application to body and scalp psoriasis plaques; two spreading surfaces designed to disperse treatment evenly across both large and small affected skin areas; and a protective cover. Patients listed the following as key Applicator attributes: ease of use, 'less messy' treatment, precise application, consistent accurate dosing, 'no touch' treatment, reduction of wasted treatment and extended length of reach for awkward areas. Although these attributes were well received by most patients and healthcare professionals, some patients did not perceive them all as improvements over their current treatment; this highlights the need to tailor treatment for each individual patient's requirements. For patients who prefer using the Applicator, it has the potential to provide greater control over their daily psoriasis management by providing a simple, convenient treatment option, with minimal impact on their lives. The Applicator may represent a more acceptable treatment 
delivery system for some patients with psoriasis vulgaris and may, therefore, promote long-term treatment adherence.

Funding: LEO Pharma

Keywords: Applicator device; Betamethasone dipropionate; Calcipotriene; Calcipotriol; Gel; Psoriasis vulgaris; Topical treatments; Topical suspension

\section{INTRODUCTION}

Poor adherence to treatment in chronic diseases is a universal challenge of striking magnitude; the World Health Organization (WHO) has calculated that adherence to long-term treatment for chronic illnesses in developed countries averages only 50\%, providing undeniable evidence that many patients experience difficulty in following treatment recommendations [1]. Irrespective of the route of administration, a drug that has demonstrated high efficacy in the acute-phase 'compliance-friendly' environment of a clinical trial may still be a therapeutic failure in the real-world setting if not accepted by the patient [2]. The reasons behind this failure can be complex and influenced by the individual patient's acceptability of the treatment [2, 3]. What is evident is a greater need for a patient-centric approach to tackle poor adherence and the WHO recognizes that interventions must be tailored to the particular illness-related demands experienced by the patient [1].

Psoriasis vulgaris is one such chronic disease that, while generally not life threatening, has no cure and can have a profound impact on a patient's physical, psychological and social well-being [4]. It is an inflammatory skin disorder that affects between $2 \%$ and $4 \%$ of
Western populations [5] and is recognized by the WHO as a painful and debilitating disease [6]. More than $80 \%$ of patients are able to manage their psoriasis with topical treatments alone [7]; however, adherence to topical treatments is poor, with one-third of prescriptions never being filled and between $39 \%$ and $73 \%$ of patients not using their medication as directed [8]. Poor adherence to topical therapy is exacerbated by the necessity of application, which can be cumbersome, messy and time-consuming [8, 9]. The fixed combination of calcipotriene $0.005 \%$ (Cal) and betamethasone dipropionate $0.064 \%$ (BD) as a topical suspension (Taclonex $^{\circledR}$ topical suspension/Daivobet ${ }^{\circledR}$ gel) is a first-line topical therapy for the once-daily treatment of all severities of psoriasis vulgaris of the scalp and body (US label), and mild-to-moderate psoriasis vulgaris of the body and all severities of psoriasis vulgaris of the scalp (EU label), in adults [10]. This topical suspension was developed to offer minimal impact on the patient's daily routine and thereby promote patient adherence [11-13].

Compared with other chronic therapy areas where drug delivery systems have been developed to assist patients in the self-management of their disease [14, 15], innovation in topical psoriasis treatment delivery systems is rare. We, therefore, undertook a program of market research and device design, in collaboration with psoriasis patients and healthcare professionals (HCPs, includes general practitioners, nurses and dermatologists), to develop a patient-friendly delivery system for Cal/BD topical suspension, which improves the treatment and application experience by meeting the needs of its end-users. In this way, we aimed to produce an Applicator that was tailored to the needs of the psoriasis patient, thereby favoring improved treatment adherence. 


\section{UNDERSTANDING THE BURDEN OF PSORIASIS}

Our initial step was to gain insights into the current issues that psoriasis patients encounter, so as to be better informed about their unmet needs. In June 2010, an initial ethnographic pilot study was performed in a small cohort of patients with psoriasis vulgaris [16]. Patients were studied for $1(n=42)$ or 2 days $(n=14)$, using a combination of interview, observation, longitudinal analysis and photo diaries. This qualitative study guided the development of a 68-part online questionnaire (completed between December 2010 and January 2011) to enable quantification of the burden of psoriasis; this online survey was endorsed by HCPs [16].

\section{Psoriasis Patients Carry a Substantial Burden of Disease}

Most patients (60\%) who completed the online questionnaire reported that psoriasis had a high impact on their daily life [16]. Physical symptoms reported by patients included pain, bleeding and most commonly itch. Itch is a distressing aspect of psoriasis [17], which can cause pronounced discomfort, is often associated with loss of sleep and can negatively impact daily activities [18]. Indeed, $54 \%$ of those patients experiencing itch also reported problems sleeping [16].

The role psychological issues play in the burden associated with psoriasis cannot be underestimated-emotional stress related to their appearance, as well as the feeling of stigmatization, is highly prevalent among patients. A quarter (27\%) of patients completing the survey agreed "my psoriasis dictates how I lead my life" [16]. Patients reported worrying about their psoriasis, that they try to hide their psoriasis and are very worried that other people perceive them as dirty. Furthermore, patients often feel dirty and constantly check their appearance. A feeling of hopelessness is also common to psoriasis patients, with $48 \%$ believing that nothing can be done about their disease [16].

\section{Topical Psoriasis Treatment is a Significant Burden in Itself}

In addition to the burden of disease, there is a considerable burden associated with psoriasis treatment, which is heightened by the chronic nature of the disease and thus the need to treat over the long term. Of those patients who completed the survey, most (92\%) were prescribed a topical treatment and less than half $(46 \%)$ indicated that they did not fully adhere to their treatment [16]. Reasons given for non-adherence included deviation from the prescribed regimen (only applying treatment when they thought it necessary; forgetting to apply it), as well as unacceptability of the treatment vehicle and its lack of convenience [16].

A further ethnographic study with both patients $(n=18)$ and HCPs $(n=19)$ was performed in 2010 to gain insight into the treatment journey and to explore the needs of individual patients (data on file, LEO Pharma). Participants contributed through 30-min telephone interviews (all patients and HCPs), 3 -h in-depth interviews at home $(n=18$ patients) and/or a 1-week diary study ( $n=15$ patients). All procedures followed were in accordance with the ethical standards of the responsible committee on human experimentation (institutional and national) and with the Helsinki Declaration of 1964, as revised in 2013. Informed consent was obtained from all patients for being included in the study. 
This study identified a number of additional challenges that psoriasis patients may face. These included a lack of control over treatment and inconsistent dosing (in contrast to other forms of medication, such as tablets, an exact daily dose of topical treatment is very difficult to manage), difficulty getting treatment out of the container (particularly patients with psoriatic arthritis), too much wastage of treatment and inability to reach awkward areas. In addition, this study aimed to generate ideas for a delivery system that patients felt would aid their treatment routine. Patients were shown a variety of off-the-shelf cosmetic and domestic products and provided feedback on whether the design of these products would be helpful in treating their psoriasis, including any modifications they could conceive may improve treatment. While patients held differing views, some design features were identified that could potentially benefit psoriasis patients, regardless of their disease status. These features related to handling ('mess-free' hands, easy to hold and the ability to reach awkward areas), application (intuitive and easy to use, precise application and reduced wastage) and packaging (easy to clean, estimation of remaining treatment and a modern visual appeal).

By adopting insights directly from psoriasis patients on the burden of psoriasis and its treatment, the aim was to develop a patient-friendly delivery system that addressed some of their previously unmet needs as detailed above; a key goal of this process was to improve their treatment experience. To maximize the potential of the delivery system, creative input and feedback were sought from both patients and HCPs throughout the development program to understand their preferences for every aspect of design.

\section{A COLLABORATIVE APPROACH TO DESIGNING THE CAL/BD TOPICAL SUSPENSION APPLICATOR}

Our objective was to provide a robust delivery system that could both dispense and disperse $\mathrm{Cal} / \mathrm{BD}$ topical suspension. To combine the patient-identified features together with technical capabilities, an applicator device was considered to be the most appropriate system, comprising a cartridge containing the topical suspension and a separate applicator head that was attached at the start of the treatment by the user.

Initially, the intention was to develop two different Applicators designed to specifically target psoriasis of the scalp or of the body. However, with insights gained from continuous testing of prototype applicators with patients and HCPs, the Applicator evolved into a single delivery system suitable for both body and scalp psoriasis. Applicator prototypes were developed with a range of features (Table 1). Over a 2-year period (2011-2013), the prototypes were assessed and modified through an iterative series of qualitative, quantitative and usability studies (Fig. 1), whereby patients $(n=12-60)$ and HCPs $(n=2-79)$ were given the opportunity to provide feedback, suggest modifications and actively contribute towards optimizing the design of the Applicator during each assessment phase (data on file, LEO Pharma).

Overall, the concept was received as a modern and innovative approach to topical psoriasis treatment application. The Applicator prototypes were perceived to be portable, robust, intuitive to handle and use and easy to store. In terms of treatment experience, patients rated the key features to be: ease of use, a 'less messy' treatment approach, precision 
Table 1 Steps taken during the design process to refine each individual feature of the calcipotriene $0.005 \%$ and betamethasone dipropionate $0.064 \%$ topical suspension Applicator

\begin{tabular}{|c|c|c|}
\hline \multirow[t]{2}{*}{ Feature } & \multicolumn{2}{|l|}{ Applicator development steps } \\
\hline & $\begin{array}{l}\text { Topical suspension Applicator } \\
\text { (for scalp application) }\end{array}$ & $\begin{array}{l}\text { Topical suspension Applicator (for body } \\
\text { and scalp application) }\end{array}$ \\
\hline \multirow[t]{3}{*}{ Spreadability } & Amount of nozzles for optimal spreading & Shape of Applicator spreading surface \\
\hline & Length of nozzles for best targeting of the scalp & Materials of spreading surface \\
\hline & & Hygiene of spreading surface \\
\hline \multirow[t]{2}{*}{ Ergonomics } & Cartridge diameter (grip size) & Cartridge diameter (grip size) \\
\hline & Cartridge and Applicator length for optimal handling & $\begin{array}{l}\text { Cartridge and Applicator length for optimal } \\
\text { handling }\end{array}$ \\
\hline Angle & $\begin{array}{l}\text { Angle of nozzle(s) for optimal scalp and hairline } \\
\text { application }\end{array}$ & $\begin{array}{l}\text { Angle of lever and spreading surface for optimal } \\
\text { scalp and body application }\end{array}$ \\
\hline \multirow[t]{2}{*}{ Nozzle } & Number of nozzles (one versus three) & One nozzle for precise application \\
\hline & Sensitivity (soft versus hard nozzles) & Larger spreading plate for larger plaques \\
\hline \multirow[t]{2}{*}{ Delivery } & Lever versus dial mechanism & Consistent dosing \\
\hline & Placement of lever on Applicator & Placement of lever on Applicator \\
\hline \multirow[t]{2}{*}{ Cover } & Cover for protecting nozzles & Cover for leakage prevention \\
\hline & & Design for cleanliness and ease of use \\
\hline
\end{tabular}

application, consistent accurate dosing, 'no touch' treatment, reduction of wasted treatment, and extended length of reach for awkward areas. The nozzle feature allows precision dispensing direct to the psoriasis plaque, thereby reducing contact with unaffected skin. The 'no touch' design negates the need to disperse the treatment with hands and/or fingers; instead, the in-built spreading surfaces can be used to perform this task. Feedback from patients indicated that a single-tip Applicator offered the widest appeal to those with scalp psoriasis by meeting certain application needs of these patients: ease of use, consistent accurate dosing, a 'less messy' treatment approach, and a reduction of wasted treatment. The single-tip nozzle was also seen to be most suitable for application to smaller body areas, such as the knuckles, whereas the large spreading surface would be able to cover large body surface areas quickly. This highlighted a significant advantage of combining both of these features into a single Applicator to create one device for both scalp and body. Two further key modifications suggested by patients were to provide an indication of the amount of topical suspension dispensed and the amount of medication remaining in the Applicator. In response to these recommendations, the amount of $\mathrm{Cal} / \mathrm{BD}$ topical suspension dispensed was included within the Applicator packaging and the Applicator plunger was made visible from the underside of the cartridge so the user is able to estimate the remaining volume of $\mathrm{Cal} / \mathrm{BD}$ topical suspension and assess when the cartridge is empty.

The key concern that patients and HCPs had with the Applicator was associated with hygiene 


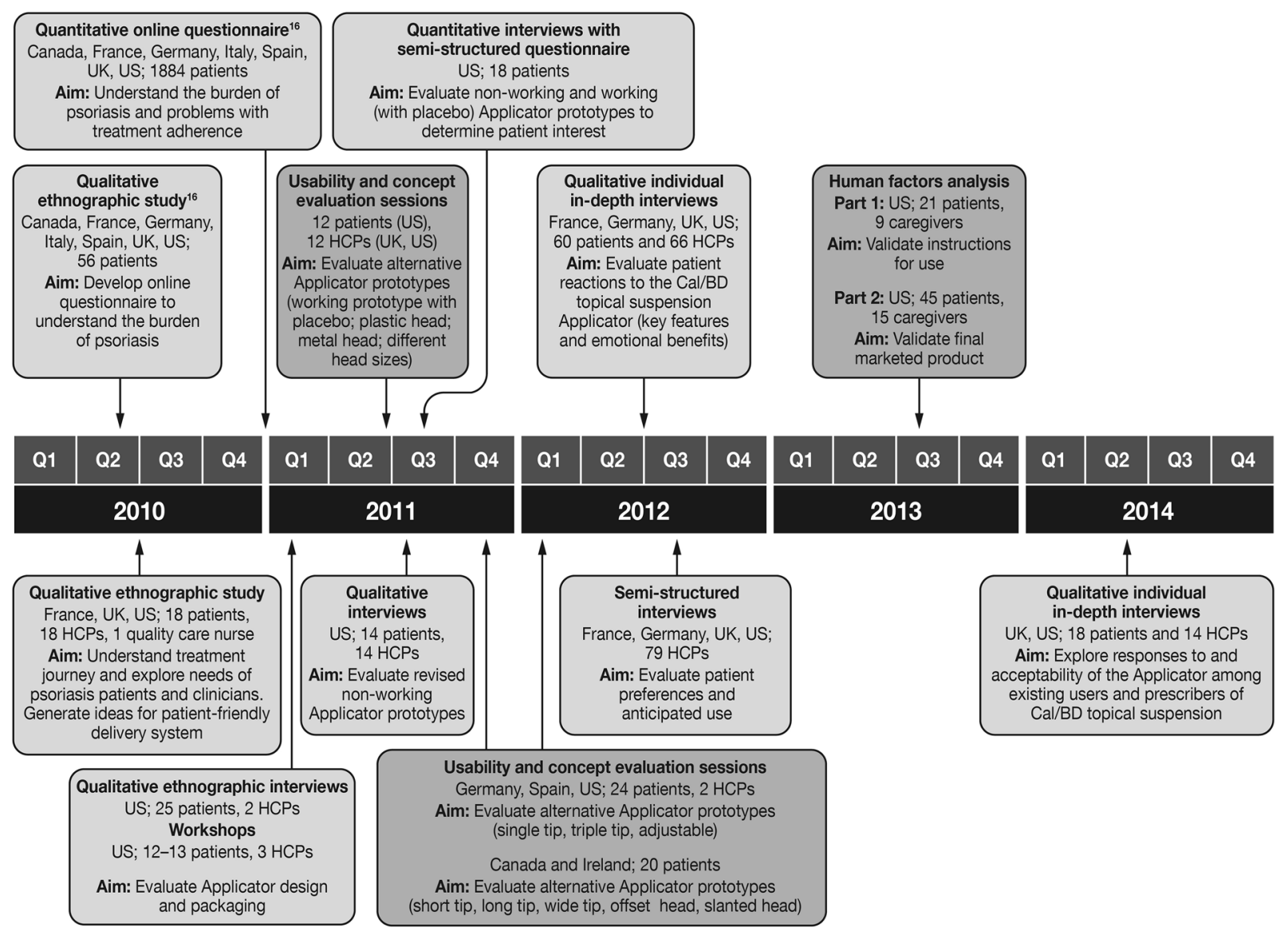

Fig. 1 Research studies undertaken to guide the design of the $\mathrm{Cal} / \mathrm{BD}$ topical suspension Applicator. Light gray indicates studies evaluating opinion and preference; dark gray indicates studies evaluating usability; participants were not shown the actual prototypes until patent applications

and wanting reassurance that cleaning the device would be effective. Microbiological testing was performed to allay these concerns. Two studies assessed the potential for contamination of the Applicator nozzle and spreading surfaces (data on file, LEO Pharma). The first study demonstrated that the recommended cleaning procedure (wiping the Applicator head with a clean, dry tissue) effectively removes an acceptable level of viable microorganisms. The second study demonstrated that although microorganisms may be transferred from the patient's skin to had been filed on the device; Cal/BD calcipotriene $0.005 \%$ and betamethasone dipropionate $0.064 \%$, HCPs healthcare practitioners (includes general practitioners, nurses and dermatologists)

the Applicator, no contamination of the Cal/BD topical suspension in the cartridge was observed.

\section{VALIDATION OF THE FINAL DESIGN OF THE TOPICAL SUSPENSION APPLICATOR}

The Applicator consists of a cartridge containing Cal/BD topical suspension and an Applicator head with a separate protective cover (Fig. 2). The Applicator has a pump-action lever that is easy to operate and provides consistently accurate dose delivery (0.05 $\mathrm{g}$ of $\mathrm{Cal} / \mathrm{BD}$ topical 
suspension/pump); a single-tip nozzle allows for targeted and precise application to psoriasis plaques; and two spreading surfaces designed to disperse Cal/BD gel evenly across both large and small areas of affected skin.

In 2013, the production version of the Applicator, including its labeling and

a

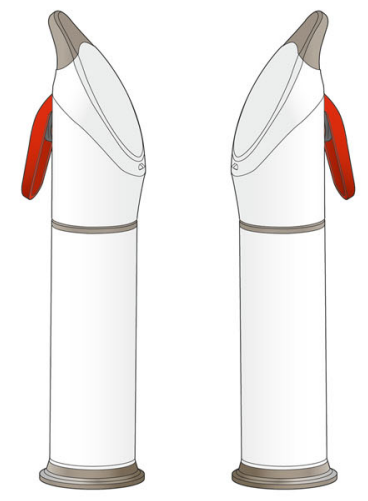

b
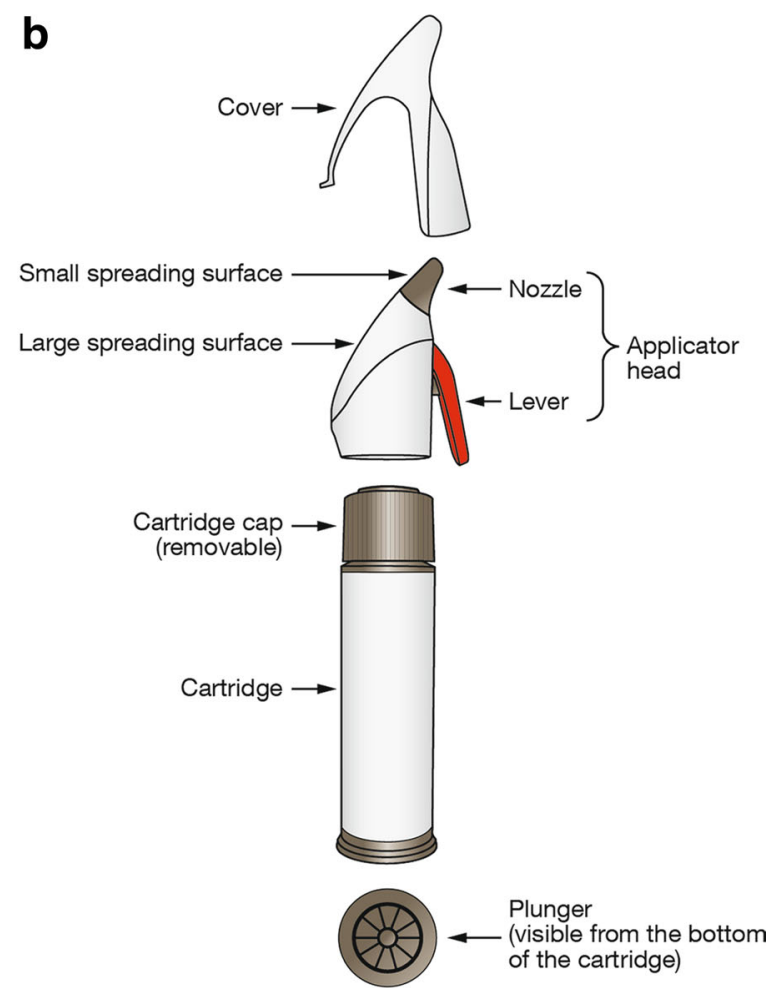

Fig. 2 Calcipotriene $0.005 \%$ and betamethasone dipropionate $0.064 \%$ topical suspension Applicator (a) and its component parts $(\mathbf{b})$ packaging, was subject to assessment in a multi-part human factor study (Fig. 1; data on file, LEO Pharma). The study was performed in a simulated-use (home-like) environment at two study centers in the US. Study participants were patients $(n=21-45)$ and carers $(n=9-15)$ who would be end-users of the Applicator. Patients were provided with an Applicator to apply non-medicated topical suspension vehicle to their own body, while carers applied the non-medicated topical suspension vehicle to a mannequin. The first part of the study focused on validating the Applicator's instructions for use; all users were prompted to consult the instructions, which led to all being able to correctly and safely assemble and use the Applicator. The second part of the study validated the design of the production version of the Applicator, as provided in its packaging. During this part of the study, participants were allowed to proceed with assembling and using the Applicator uninterrupted to ensure a scenario as close to 'real life' as possible. All patients and carers were able to use the Applicator correctly and safely to either self-apply or assist with application of topical suspension vehicle; indeed participants in both parts of the study rated the Applicator above average for ease of use (Fig. 3), requiring little assistance from the instructions for use to successfully assemble and apply placebo topical suspension vehicle. Notably, all patients with physician-diagnosed arthritis in their hands $(n=10)$ were able to grip the Applicator and dispense Cal/BD topical suspension without difficulty. The human factor validation analysis additionally concluded there were no unacceptable risks associated with use of the Applicator. 

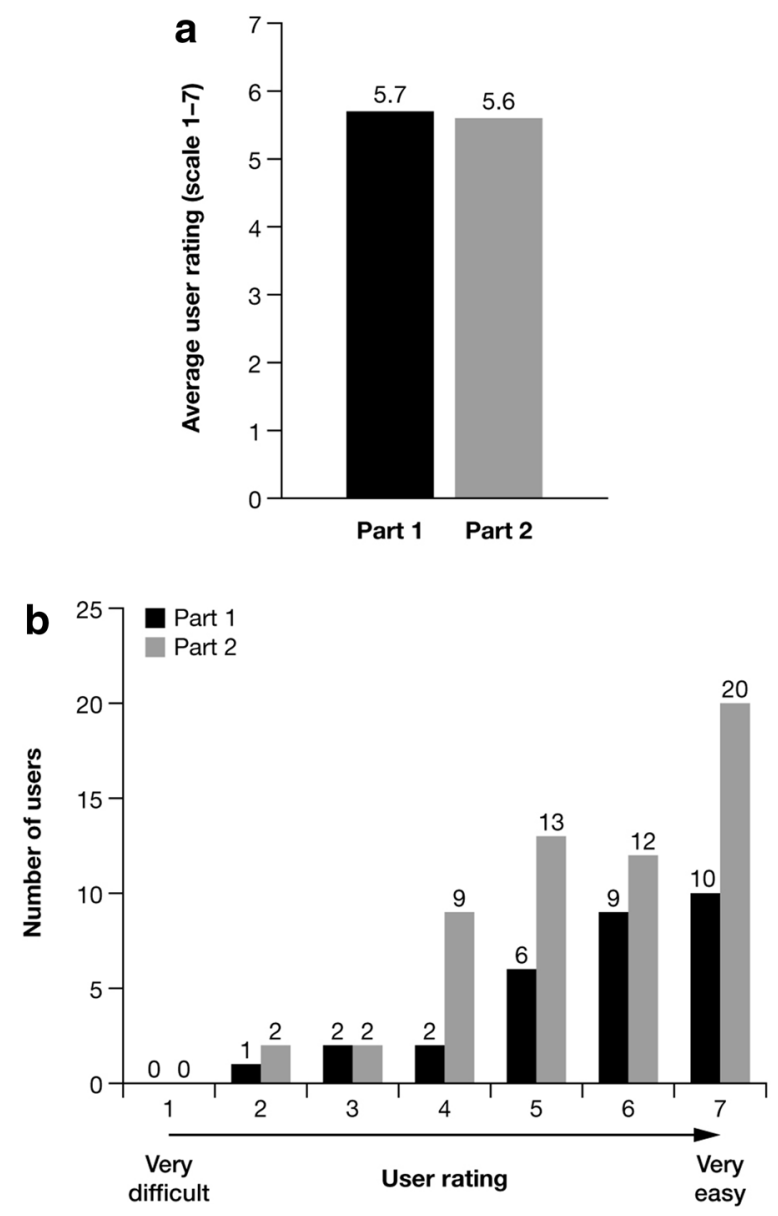

Fig. 3 Average user rating (scale 1-7) of the calcipotriene $0.005 \%$ and betamethasone dipropionate $0.064 \%$ topical suspension Applicator in the human factors study to validate the instructions for use (part 1 ) and to validate the final Applicator design as provided in its packaging (part 2) (a) and a breakdown of the individual user scores (b)

\section{EVALUATING THE FINAL DESIGN OF THE TOPICAL SUSPENSION APPLICATOR}

The concluding phase of development was evaluation of the Applicator by existing users $(n=18)$ and prescribers $(n=14)$ of $\mathrm{Cal} / \mathrm{BD}$ topical suspension (Fig. 1). Two streams of qualitative individual interviews were performed to explore patient response and acceptability and physician perspectives on the device. Patient response was positive with $89 \%$ indicating they preferred the Applicator to the existing presentation of $\mathrm{Cal} / \mathrm{BD}$ topical suspension in a bottle; their preference was primarily based on the Applicator offering consistent and controlled dosing and precise delivery of treatment to target areas (data on file, LEO Pharma). Other positive responses included an enhanced ability to reach 'hard-to-reach' or 'hard-to-see' areas and better control over dosing for scalp application. Approximately, one-quarter of the patients (28\%) indicated the 'no touch' feature was a major attribute of the Applicator. Most of the surveyed physicians also recognized the same benefits of the Applicator as highlighted by the patients, although it was clear that these benefits appealed more to patients than physicians. Furthermore, only one physician, who had personal experience of a skin condition, spontaneously identified the 'no touch' option as a benefit.

\section{WHAT DOES THE APPLICATOR DELIVERY SYSTEM OFFER PATIENTS?}

The value of the Applicator design is firmly based on the insights gained from the patients during the development process; having handled and used the Applicator prototypes, patients were able to identify issues that were previously not fully appreciated. In so doing, we believe the Applicator has the potential to be a key step toward bridging the gap in topical psoriasis treatment, offering features that address a number of unmet patient needs. Key attributes of the Applicator are discussed below.

\section{Consistently Accurate Dosing and Precision Application}

Dosing of psoriasis topical treatments has historically relied on a relatively inaccurate and subjective tool for measurement-the 
'fingertip unit' (FTU). This is defined as the amount of topical treatment expressed from a 5 -mm-diameter nozzle and applied from the distal skin crease to the tip of the index finger of an adult; two FTUs approximately equate to $1 \mathrm{~g}$ of topical treatment [7]. Concern arises with patients because they are not prescribed an exact daily dose, which leads to the perception that they have poor control over the day-to-day management of their psoriasis, both with overand with under-treatment. With the consistently accurate dosing feature of the Applicator (0.05 g of topical suspension/ pump), patients will be able to accurately monitor and tailor the amount of topical suspension they are using each day, which should allow them to feel more reassured in managing the amount of treatment product that they are applying to their skin, avoiding ambiguities and allaying worries about the dose level. Additionally, the consistently accurate dosing feature may enable HCPs to provide guidance and recommendations to patients regarding topical treatment dose.

The nozzle and small spreading area allow precise and targeted application of treatment, which will minimize exposure of healthy, unaffected skin to treatment. This has the potential to be especially useful for those patients with only small areas of affected skin, as well as those needing to treat their scalp, providing a greater level of control in their daily treatment regimen.

\section{'No Touch' Treatment}

During the development of this Applicator, it became apparent from patient feedback that there is a clear distinction between those who want or need to have physical contact with their plaques and those who do not want to touch them. With the 'no touch' feature, the
Applicator allows the latter subgroup of patients to apply treatment to affected areas without the need for physical contact. This feature may be an important consideration when treatment is applied by a third party/caregiver-patients may feel less self-conscious if the carer does not have direct contact with their plaques, and it will also reduce the carer's contact with the topical suspension, decreasing their exposure to the active ingredients. This feature of the Applicator also makes it possible for patients and carers to apply the treatment without getting greasy hands and removes the necessity to wash hands after use, thus reducing the number of treatment steps.

\section{Neater and Less Messy}

Current topical treatments are largely available in tubes and bottles, which according to patient feedback may crack and leak, meaning patients need to take extra care in storing and transporting these products. The Applicator has been designed to be a robust delivery system that does not break, with a protective cover to prevent accidental delivery or leakage. These features may be of particular importance to patients because of the potential for increased convenience and reduced disruption of their daily routine.

\section{Improved Convenience}

The Applicator offers various attributes designed to appeal to a diverse range of psoriasis patients by providing simple solutions to overcome some of their previous unmet needs. In doing so, a reduction in treatment burden would be expected, resulting in greater convenience to these patients. In addition, for those who currently have to rely on assistance with treatment application, the 
Applicator has the potential to offer increased independence, which can further allow the patient a greater feeling of control.

The Applicator is easy to use; it is ergonomically shaped to be held comfortably in the hand, and it is easy to dispense and apply treatment directly to psoriasis plaques. This feature should be of particular benefit to those patients who are less dextrous, such as those with psoriatic arthritis, who struggle to open tubes and bottles. The Applicator also provides patients with extended reach for direct and targeted application to some hard-to-reach/ hard-to-see areas, both on the body and on the scalp. As an example, for those who lack the flexibility to reach their lower legs and feet, the extended reach of the Applicator may be able to aid treatment application without the need to rely on a carer.

\section{ONE SIZE DOES NOT FIT ALL}

Overall, the Applicator was very well received by most patients and HCPs who participated in its development and final assessment. The research demonstrated that patients identified many different attributes of the topical suspension Applicator address some of their unmet needs. However, it was apparent that some patients do not recognize the attributes of the Applicator as beneficial to themselves and remain loyal to their current treatment. These observations indicate that resolving treatment adherence is not a simple matter-patients are individuals who have different experiences and expectations of topical treatments and see value in different aspects of treatment. Given the most common treatment-related reasons for non-adherence include treatment inconvenience $(23 \%)$ and the treatment being too messy (16\%), the attributes of the Applicator described herein may have the potential to improve adherence. However, certain attributes of the Applicator are likely to be met more favorably than others within particular patient types, such as the 'no touch' feature, which appealed to those not wishing to touch their plaques but not to those needing physical contact with their skin as an essential part of therapy. The studies described here highlight the importance of tailoring treatment to the needs of each patient [1].

\section{CONCLUSION}

The Cal/BD topical suspension Applicator is an innovative delivery system within the psoriasis therapy area. The foundations of its innovation are in the collaborative approach adopted in its development, gaining insight from patients and HCPs throughout the process and resulting in a drug delivery system with a range of attributes, addressing a number of unmet needs as communicated by patients with psoriasis. However, the Applicator will not be every patient's preferred choice, and each patient should have their own treatment tailored to their requirements. For those who do gain benefit from the Applicator, it has the potential to allow them greater control over the self-management of their psoriasis by providing a more simple and convenient treatment option that has minimal impact on their lives. In so doing, the Applicator may become the treatment of choice for some patients; in those patients, the Applicator may promote treatment adherence over the long term as a more acceptable therapy option.

\section{ACKNOWLEDGMENTS}

This study was sponsored and article processing charges were funded by LEO Pharma. We would 
like to thank all of the patients who participated in our studies and provided vital contributions during the development of the Applicator. We would also like to thank Diane Chayer, the Patients Insights Manager who headed all the market research with the Global Patient Solutions Managers and Karsten Petersson, Principal Scientist who initiated the voyage of the Applicator project. We also thank RED associates, Jon Chandler from Mojo, Alex Crook, Steven McLellan, Peter Sprada, Nick Reddall, Graham Lacy and Alun Wilcox from PDD Group Ltd, Søren Larsen from Biometer International A/S, Angela Duffy, Mark Braund, Danielle Christmas, Loren Watling, David Orton and Jenny Summers from the research partnership and Phoenix Healthcare for conducting research studies. We would like to thank Thomas Varricchione, Tatyana Budantsev, Jimmy Wong and Pamela Davol from Ximedica for conducting the full product validation study. All named authors meet the International Committee of Medical Journal Editors (ICMJE) criteria for authorship for this manuscript, take responsibility for the integrity of the work as a whole, and have given final approval to the version to be published. Additionally, we thank Catherine Risebro, PhD, from Mudskipper Business Ltd, who provided medical writing support funded by LEO Pharma.

Disclosures. G. Rasmussen, L. Lillevang Bech and T. Nielsen are employees of LEO Pharma.

Compliance with ethics guidelines. All procedures followed were in accordance with the ethical standards of the responsible committee on human experimentation (institutional and national) and with the Helsinki Declaration of 1964, as revised in
2013. Informed consent was obtained from all patients for being included in the study.

Open Access. This article is distributed under the terms of the Creative Commons Attribution-NonCommercial 4.0 International License (http://creativecommons.org/licenses/ by-nc/4.0/), which permits any noncommercial use, distribution, and reproduction in any medium, provided you give appropriate credit to the original author(s) and the source, provide a link to the Creative Commons license, and indicate if changes were made.

\section{REFERENCES}

1. World Health Organization. Adherence to long-term therapies. Evidence for action. 2003. http://whqlibdoc.who.int/publications/2003/924154 5992.pdf.

2. Osterberg L, Blaschke T. Adherence to medication. N Engl J Med. 2005;353:487-97.

3. Thorneloe RJ, Bundy C, Griffiths CE, et al. Adherence to medication in patients with psoriasis: a systematic literature review. $\mathrm{Br} \mathrm{J}$ Dermatol. 2013;168:20-31.

4. Bhosle MJ, Kulkarni A, Feldman SR, et al. Quality of life in patients with psoriasis. Health Qual Life Outcomes. 2006;4:35.

5. Parisi R, Symmons DP, Griffiths CE, et al. Global epidemiology of psoriasis: a systematic review of incidence and prevalence. J Invest Dermatol. 2013;133:377-85.

6. World Health Organization. Psoriasis: Sixty seventh World Health Assembly Agenda item 13. 5. 2014. http://apps.who.int/gb/ebwha/pdf_files/WHA67/A67_ R9-en.pdf. Accessed 19 Oct 2015.

7. Menter A, Korman NJ, Elmets CA, et al. Guidelines of care for the management of psoriasis and psoriatic arthritis section 3. Guidelines of care for the management and treatment of psoriasis with topical therapies. J Am Acad Dermatol. 2009;60:643-59.

8. Bewley A, Page B. Maximizing patient adherence for optimal outcomes in psoriasis. J Eur Acad Dermatol Venereol. 2011;25(Suppl 4):9-14. 
9. Devaux S, Castela A, Archier E, et al. Adherence to topical treatment in psoriasis: a systematic literature review. J Eur Acad Dermatol Venereol. 2012;26(Suppl 3):61-7.

10. Menter A, Stein Gold L, Bukhalo $M$, et al. Calcipotriene plus betamethasone dipropionate topical suspension for the treatment of mild to moderate psoriasis vulgaris on the body: a randomized, double-blind, vehicle-controlled trial. J Drugs Dermatol. 2013;12:92-8.

11. Reich K, Zschocke I, Bachelez H, et al. Efficacy of a fixed combination of calcipotriol/betamethasone dipropionate topical gel in adult patients with mild to moderate psoriasis: blinded interim analysis of a phase IV, multicenter, randomized, controlled, prospective study. J Eur Acad Dermatol Venereol. 2014;26:1156-63.

12. Lambert J, Griekspoor M, Vink J. Patient-reported effectiveness for calcipotriol and betamethasone dipropionate gel and ointment formulations in psoriasis vulgaris: 4- and 12-week interim results from PRO-long. 22nd Congress of the European Academy of Dermatology and Venereology (EADV). Istanbul, Turkey; 2-6 Oct 2013; abst P1590.

13. Lambert J, Hol CW, Vink J. Real-life effectiveness of once-daily calcipotriol and betamethasone dipropionate gel vs. ointment formulations in psoriasis vulgaris: 4- and 12-week interim results from the PRO-long study. J Eur Acad Dermatol Venereol. 2014;28:1723-31.

14. Hall RL, Willgoss T, Humphrey LJ, et al. The effect of medical device dose-memory functions on patients' adherence to treatment, confidence, and disease self-management. Patient Prefer Adherence. 2014;8:775-88.

15. Sorli C. New developments in insulin therapy for type 2 diabetes. Am J Med. 2014;127:S39-48.

16. Bewley A, Burrage DM, Ersser SJ, et al. Identifying individual psychosocial and adherence support needs in patients with psoriasis: a multinational two-stage qualitative and quantitative study. J Eur Acad Dermatol Venereol. 2013;28:763-70.

17. Kimball $\mathrm{AB}$, Jacobson $\mathrm{C}$, Weiss $\mathrm{S}$, et al. The psychosocial burden of psoriasis. Am J Clin Dermatol. 2005;6:383-92.

18. Globe D, Bayliss MS, Harrison DJ. The impact of itch symptoms in psoriasis: results from physician interviews and patient focus groups. Health Qual Life Outcomes. 2009;7:62. 